\title{
CBCT of maxillary central incisor with internal resorption: a case report
}

\author{
Khamila Gayatri Anjani ${ }^{*}$, Fahri Reza Ramadhan', Azhari²
}

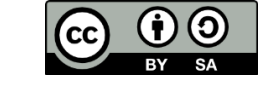

This work is licensed under a
Ceative Commons Attribution 4.0 ich permits use, distribution and reproduction provided that the original work is properlyctitited,
the use is non-commercial and no modification adaptations are made.
and
${ }^{1}$ Dentomaxillofacial Radiology Residency Program, Faculty of Dentistry, Universitas Padjadjaran, Bandung, Indonesia 40132

${ }^{2}$ Department of Dentomaxillofacial Radiology, Faculty of Dentistry, Universitas Padjadjaran, Bandung, Indonesia 40132

*Correspondence to:

Khamila Gayatri Anjani

■khamila20001@mail.unpad.ac.id

Received on: October 2021 Revised on: November 2021 Accepted on: December 2021

\begin{abstract}
Objectives: The aim of this case report is to report the radiographic features of an internal resorption in maxillary central incisor and to emphasize the benefits of $\mathrm{CBCT}$ in this case.
\end{abstract}

Case Report: A 14-year-old male went to Universitas Padjadjaran Dental Hospital with a discoloration of his fracture upper anterior teeth. The anamnesis revealed that the patient had history of a fall in about 6 years ago. Patient didn't complain about pain when examination happened and wanted to have his teeth treated. Periapical

radiograph showed an internal resorption in maxillary central incisor. Cone beam computed tomography (CBCT) was used to see other findings before determining the treatment plan.

Conclusion: Internal resorption gives a characteristic appearance on the radiograph. CBCT modalities provide more information than conventional ones so that the use of this modality is not only to establish a diagnosis, but also can be used in determining the right treatment plan.

Keywords: Cone beam computed tomography, internal resorption, trauma Cite this article: Anjani KG, Ramadhan FR, Azhari. CBCT of maxillary central incisor with internal resorption: a case report. Jurnal Radiologi Dentomaksilofasial Indonesia 2021;5(3)122-5. https://doi.org/10.32793/jrdi.v5i3.736

\section{INTRODUCTION}

Anatomically, a normal tooth consists of crown and root. Dental root is bordered by precementum at the outside surface, and predentine at the inner surface. Tooth resorption presents itself either as a physiological or a pathological process occurring internally (pulp-derived) or externally (periodontally derived). According to the Glossary of The American Association of Endodontists, resorption is defined as a condition associated with either a physiologic or a pathologic process resulting in the loss of dentin, cementum, or bone. ${ }^{1}$

Root resorption can be defined as either internal or external root resorption. When these structures are destroyed by infections, mechanical or chemical causes, root resorption may occur. ${ }^{2}$ Internal resorption is a rare, insidious, resorptive pathological process, beginning in the pulpal space and extending into surrounding dentin. ${ }^{1}$ Internal resorption is an inflammatory process that starts in the pulp area and results in the loss of dentin and possible invasion of the cementum. ${ }^{3}$

In most of the cases, the internal resorption usually is asymptomatic and detectable by routine radiographs. Usually, internal root resorption appears as a "ballooning-out" of the root canal in radiographs. The resorption lesion is radiolucent and has smooth, well-defined margins and is oval or round. ${ }^{4}$ The presence and the location of the resorption were radiographically observed that the internal resorption was prevalent in $2.16 \%$ of the cases, with $0.86 \%$ located in coronal region, $0,44 \%$ in root region and $0.86 \%$ in both regions. ${ }^{5}$

Accurate assessment is essential as the treatment protocols may vary. Root resorption may be confirmed using intraoral radiograph. However, intraoral radiographs do not provide an indication of the true dimensions of such lesions. The resorption defect may spread in all directions, this may not be reflected on the radiographs. ${ }^{4}$ and not considered reliable for early diagnosis due to the difficulty in distinguishing lesions on the buccal or lingual/palatal surfaces. ${ }^{6}$ Cone beam computed tomography (CBCT) generates images in the axial, coronal, and sagittal directions, allowing threedimensional visualization of dental structures which helps dental practitioners to get many information before determining the proper treatment plan. CBCT gives information about the lesion size, shape, and location, presence of root perforations, apical bone lesion, root wall thickness, localization of anatomical structures, the differential diagnosis and prognosis of root resorption. ${ }^{8}$ In this case, from periapical radiograph root canal treatment is planned. The patient was guided to take CBCT imaging before the treatment. The same radiodiagnosis was made but the treatment was different from the first. The aim of this paper is to report the radiograph features of internal 
resorption in maxillary right central incisor and to emphasize the use of CBCT in diagnosing and taking a decision of treatment plan.

\section{CASE REPORT}

A 14-year-old male went to Universitas Padjadjaran Dental Hospital with a discoloration of his fracture upper anterior teeth. The history revealed that the patient had trauma to the tooth about 6 years ago and that the tooth was fractured horizontally. The patient didn't complain about pain when examination happened and wanted to have his teeth treated. On clinical examination, there were no symptoms other than sensitivity on percussion test. Radiological examination of the maxillary right central incisor revealed loss of crown structure partly, with one straight root which shows extension of root canal to lateral. The periapical showed enlargement of periodontal membrane. Internal resorption with chronic apical periodontitis was suspected in this case through the periapical radiograph and root canal treatment is planned. The patient was guided to take CBCT imaging before the treatment. The same radiodiagnosis was made.

Coronal view of CBCT showed the width (mesial -distal) of extension root canal $5,42 \mathrm{~mm}$ with enlargement of periodontal membrane in $1 / 3$ apical. Axial sliced view showed the tooth from crown to apex and its relation to foramen incisivum. Enlargement of periodontal membrane also seen in sagittal view with extension of root canal 4,67 $\mathrm{mm}$ in width (labio-palatal). In sagittal view also, discontinuity labial part of the root in cervical was presented. This information leads to different treatment planning from root canal treatment to an extraction.

\section{DISCUSSION}

Dentists usually have a clinical issue when treating a tooth with internal resorption. It needs some consideration to decide the proper treatment whether treat it endodontically with a poor prognosis or extract. Tooth resorption could go unnoticed for months or even years, and there are rarely any symptoms unless it is linked with substantial pulpal inflammation or periodontal ligament. Visual examination of this abnormality is usually based on the presence of a pink spot in the dental crown. Other examination, like conventional and cone beam computed tomography, can be used to help establishing the diagnosis of internal resorption. ${ }^{9}$

Internal resorption is characterized by resorption on the inner surface of the dentine adjacent to the granulation tissue produced in the pulp. Destruction of dental hard tissues in internal resorption occurs with odontoclastic activity. ${ }^{2}$ In the inflammatory resorption, the intraradicular dentin resorption process proceeds without the deposition of hard structures next to the resorption sites. The occurrence is linked to the existence of granulation tissues in the resorbed area, which can be seen as a radio clear zone centered on the root canal on routine radiographs. ${ }^{3}$ In this pattern the area of destruction usually appears as a uniform wellcircumscribed symmetric radiolucent enlargement of the root canal. ${ }^{10}$ It is characteristic radiographic sign that the internal pulpal wall is destroyed, whereas cementum and periodontium are not affected. Similar to other inflammatory resorptive defects, the histologic picture of internal resorption is granulation tissue with multinucleated giant cells. An area of necrotic pulp is found coronal to the granulation tissue. Dentinal tubules containing microorganisms and communication between the necrotic zone and the granulation tissue can sometimes be seen. ${ }^{11}$

The cause of internal inflammatory resorption is unknown; however, some studies implicate dental trauma as one factor triggering resorption. ${ }^{7}$ Usually, internal resorption is asymptomatic. It has been reported that internal resorption is more common in males than females. ${ }^{2}$ In our case, the patient was male, triggered by trauma, and asymptomatic.

Resorption is usually detected by periapical
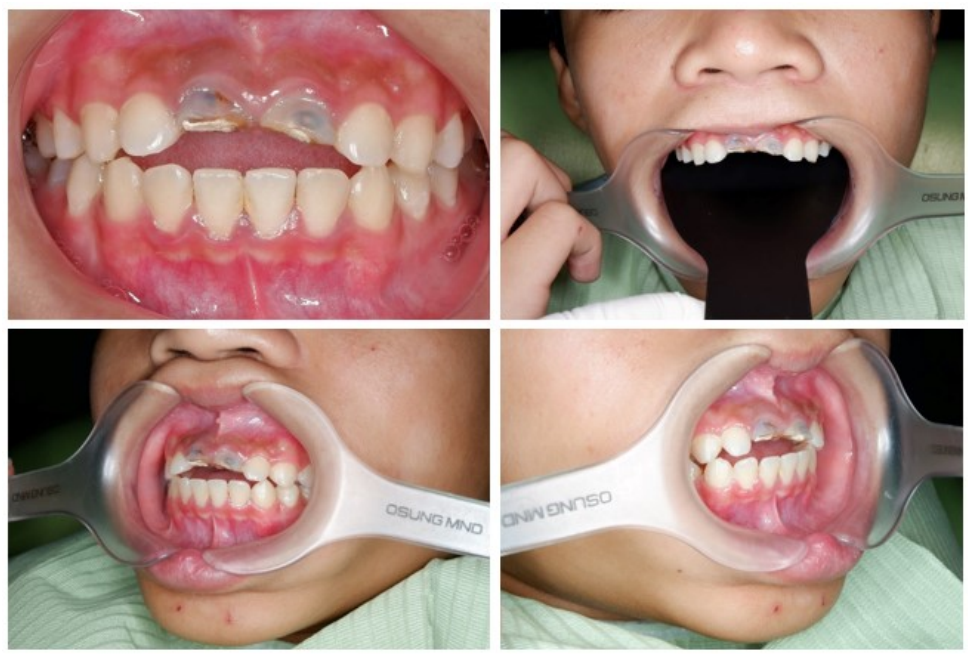

Figure 1. Pre-treatment intra-oral photographs

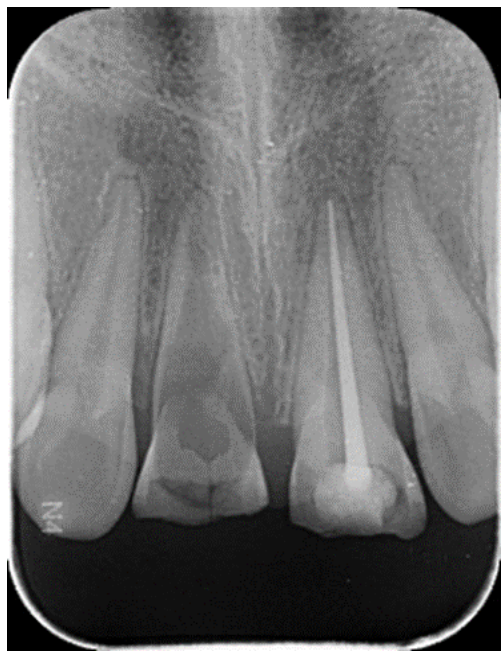

Figure 2. The widening of root canal was seen in tooth 11 

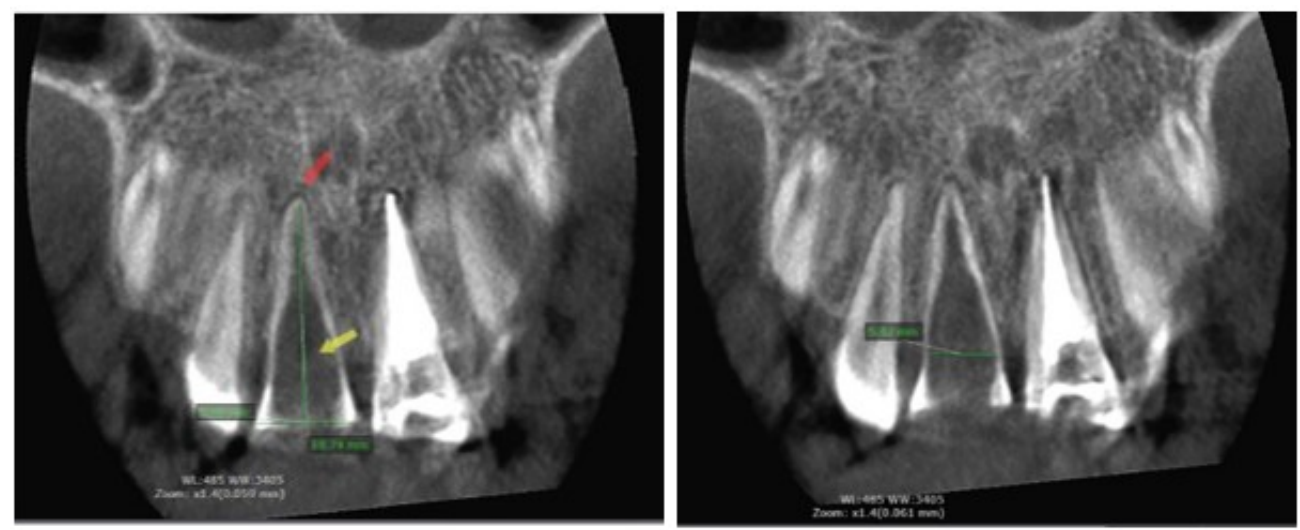

Figure 3. Reconstructed $\mathrm{CBCT}$ image in coronal view showing tooth 11 with its edited information

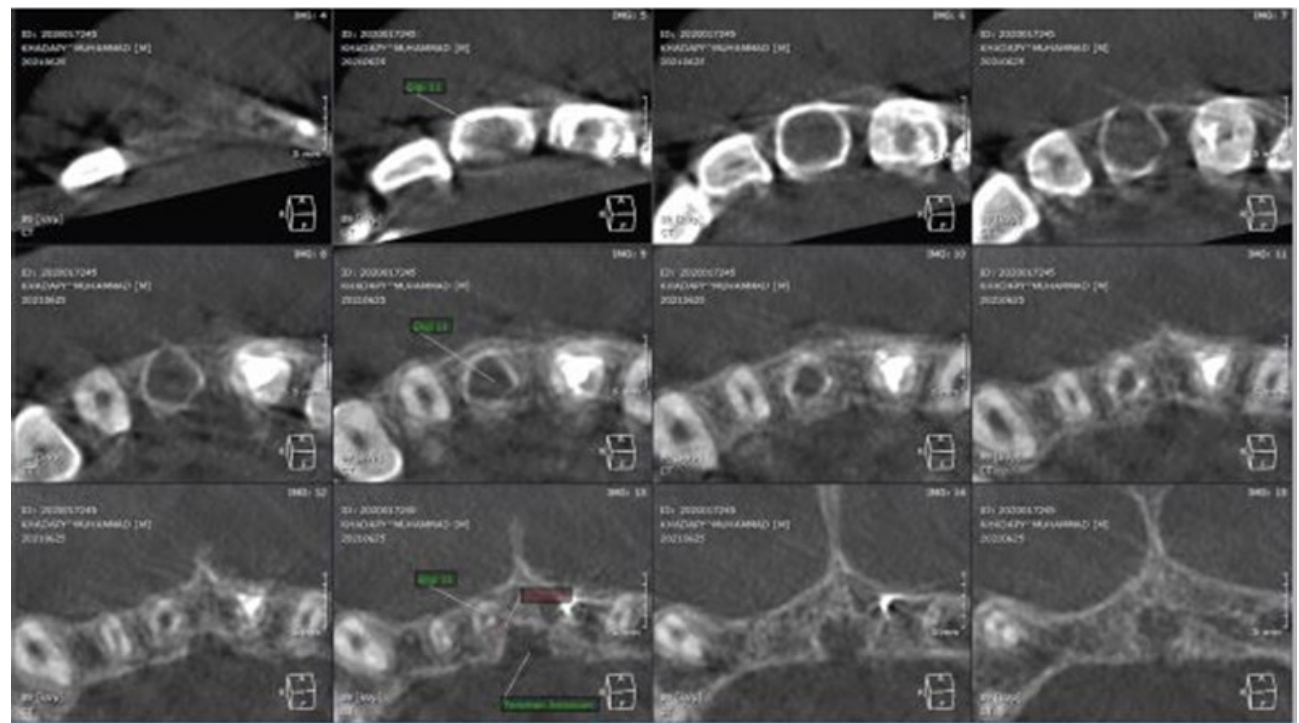

Figure 4. Reconstructed $\mathrm{CBCT}$ image in axial view
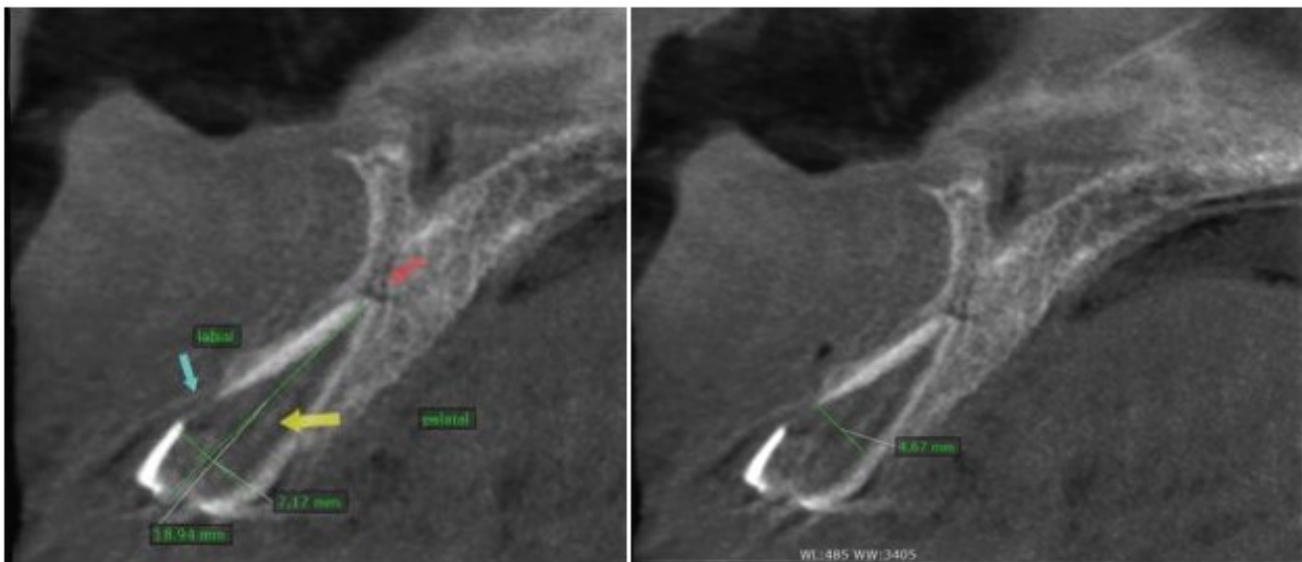

Figure 5. Reconstructed $\mathrm{CBCT}$ image in sagittal view showing tooth 11 with its edited information

radiography. However, the two-dimensional nature of these images makes periapical radiograph inaccurate in determining the location, severity, and type of resorption. This has been confirmed in several studies. ${ }^{7,12}$ The diagnosis of internal resorption is primarily based on radiographic examination, with additional information drawn from the history and clinical findings. The internal root resorption lesions are smooth and usually symmetrically distributed over the root. The radiolucency of the internal root resorption has uniform density, and the root canal can not be followed through the lesion, because the canal walls essentially balloon out. ${ }^{4,13}$

CBCT images precisely reproduce maxillofacial tissues and elucidate the presence of periapical lesions more accurately than conventional radiographs. ${ }^{14}$ The use of CBCT has substantially 
improved the diagnosis of internal resorption nowadays. Furthermore, the CBCT enhanced diagnosis accuracy resulted in better defect treatment and a prognosis of conservative therapy for teeth with internal resorption. ${ }^{2}$ That is why we believe that CBCT does not only allow a better resorption diagnosis, but, since it gives us more data, it allows clinicians to establish the most appropriate treatment. ${ }^{12}$ In our case, we used CBCT to predict a possible perforation due to an irregular and large resorption area.

Treatment of internal root resorption is conceptually not complicated. Since the resorptive defect is the result of the inflamed pulp and the blood supply to the tissue is through the apical foramina, endodontic treatment that effectively removes the blood supply to the resorbing cells is the treatment approach. ${ }^{11}$ In teeth with perforating defects, remineralization of the defect may occur, formation of hard tissue matrix against which permanent root canal filling is condensed or surgical approach and some cases may require extraction. ${ }^{15}$

Our case was planned to have a root canal treatment before the result of $\mathrm{CBCT}$ was given. There are several criteria that was described by Nilsson et $a l^{3}{ }^{3}$ regarding the management of internal root resorption; patient's age, tooth location, shape of the clinical crown, occlusion, resorption location, resorption wideness, presence or not of root perforations and their wideness, resistance/weakness of the remaining root hard tissue, periodontal status, ability to realize a restorative treatment of the concerned tooth. ${ }^{3}$ This information could be collected from clinical and other examination, like radiograph. After the result of $\mathrm{CBCT}$ showed presence of a perforation, treatment plan to extract the teeth was made.

This case report demonstrates the advantages of employing CBCT imaging to diagnose, assess, and monitor internal resorption in the presence of apical chronic periodontitis. The capacity of the clinician to make a confirmed diagnosis and determine a treatment strategy is enhanced by the $\mathrm{CBCT}$ examination. The severity of interna resorption could not be determined only based on two-dimensional radiographs. Furthermore, $C B C T$ imaging provides a non-invasive, repeatable method for evaluating root canal systems in three dimensions.

\section{CONCLUSION}

The ability to analyze the region of interest in any plane without distortion and eliminate artifacts associated with conventional radiography is essential for using CBCT to demonstrate internal resorption. Radiograph feature of an internal resorption is the widening of root canal. $\mathrm{CBCT}$ could give more information as to consider the management of the teeth. The use of CBCT examination in this case is not only for diagnostic needs, but also as a consideration to a proper treatment plan.

\section{ACKNOWLEDGMENTS}

None.

\section{FOOTNOTES}

All authors have no potential conflict of interest to declare for this article. Informed consent was obtained from the patient for being included in this case report.

\section{REFERENCES}

1. Thomas $\mathrm{P}$, Krishna Pillai R, Pushparajan Ramakrishnan $B$, Palani J. An Insight into Internal Resorption. ISRN Dentistry. 2014;2014:1-7.

2. Karakaya G, Can G, Turkaydin D, Iriboz E, Ovecoglu HS Treatment of maxillary central incisors with internal resorption: Two case reports. Turk Endod J. 2019;4(2):39-43.

3. Nilsson E, Bonte E, Bayet F, Lasfargues JJ. Management of internal root resorption on permanent teeth. Int J Dent. 2013;2013:929486

4. Sangavi T, Karthick A, Malarvizhi D, Venkatesh A Management of internal root resorption: A Review. European Journal of Molecular \& Clinical Medicine, 2020; 7(10): 658-62.

5. Araújo LCG de, Lins CV, Lima GA de, Travassos RMC, Lins CC dos SA. Study of Prevalence of Internal Resorption in Periapical Radiography of Anteriors Permanents Tooth. International Journal of Morphology. 2009;27(1):227-30.

6. Levin MD, Jong G. The use of CBCT in the diagnosis and management of root resorption. In: 3D Imaging in Endodontics: A New Era in Diagnosis and Treatment. Springer International Publishing; 2016. p.131-43.

7. Lima TF, Gamba TO, Zaia AA, Soares AJ. Evaluation of cone beam computed tomography and periapical radiography in the diagnosis of root resorption. Australian Dental Journal. 2016 Dec 1;61(4):425-31.

8. Da AG, Limoeiro S, Baetz S, Galvani M, Fabiano K, Pereira S, et al. CONE-BEAM COMPUTED TOMOGRAPHY APPLICATIONS IN ENDODONTICS: TWO CASES REPORT. Journal of Surgical and Clinical Dentistry-JSCD [Internet]. 18(1):8-11.

9. Karanath SA, Geeta I, James JM. Management of Internal Resorption: A Catch-22 Situation. Journal of Operative Dentistry \& Endodontics. 2017;2(1):31-5.

10. Datana S, Radhakrishnan V. Internal resorption: An unusual form of tooth resorption. Medical Journal Armed Forces India. 2011;67(4):364-6.

11. Ingle $\mathrm{Jl}$, Bakland LK, Baumgartner JC, Ingle Jl.Ingle's endodontics 6. Hamilton, Ontario: BC Decker; 2008.

12. Fornara $\mathrm{R}$, Re Cecconi D. Importance of $\mathrm{CBCT}$ in the management plan of upper canine with internal resorption. Giornale Italiano di Endodonzia. 2015;29(2):70-6.

13. Maini A, Durning P, Drage N. Resorption: Within or without? The benefit of Cone-Beam Computed Tomography when diagnosing a case of an internal/external resorption defect. British Dental Journal. 2008 Feb 9;204(3):135-7.

14. Bendyk-Szeffer $M$, Łagocka $R$, Trusewicz $M$, Lipski $M$, Buczkowska-Radlińska J. Perforating internal root resorption repaired with mineral trioxide aggregate caused complete resolution of odontogenic sinus mucositis: A case report. Journal of Endodontics. 2015;41(2):274-8.

15. Mittal S, Kumar T, Mittal S, Sharma J. "Internal root resorption: An endodontic challenge": A case series. J Conserv Dent. 2014;17(6):590-3. 